\title{
Apresentação Água Viva 2018.2
}

A Revista Água Viva tem por objetivo promover a circulação dos artigos resultantes das pesquisas de acadêmicos da área da Literatura - que acontecem majoritariamente no âmbito das universidades. Em um momento em que tanto as universidades quanto outras organizações dedicadas à pesquisa, no país, sofrem objetivamente cortes no orçamento e são sujeitas a ataques que as desabonam, é ainda mais importante manter a circulação de ideias. Assim, apresento a seguir os artigos resultantes da atividade de pesquisa de muitas pessoas dedicadas a criar e disseminar conhecimento.

Apresentando um arcabouço teórico robusto, baseado em Propp, Campbell e Vogler, Pedro Afonso Barth, em A JORNADA DO HERÓI EM A GUERRA DOS TRONOS: EDDARD STARK, UM HERÓI DESCONSTRUÍDO, analisa um dos personagens de Crônicas do Gelo e do Fogo, de R. R. Martin. Eddard Stark percorre a trajetória do herói, como o autor demonstra, no entanto, há uma ruptura no momento em que, apesar de ter cumprido os passos anteriores, no confronto com o inimigo que deveria resultar em vitória e conquista, Eddard é traído e executado. Essa ruptura só pode acontecer pois toda a teoria elaborada por Propp e Campbell se baseia em narrativas nas quais há uma distinção inequívoca entre bem e mal. O mundo de A Guerra dos Tronos, ao contrário, é ambíguo e a nobreza não é necessariamente recompensada. No entanto, isso não implica, necessariamente, um rompimento com o arquétipo do herói, uma vez que uma das características da obra é entrelaçar várias narrativas e Eddard, apesar de parecer ser o protagonista, na verdade não o é.

Claudio Alves Benassi apresenta, em O QUE DIZEM OS NÚMEROS: UMA LEITURA NUMEROLÓGICA PITAGÓRICA DO POEMA SINALIZADO CORAÇÃO FECHADO (2017), DE CAO BENASSI, uma leitura de um poema em Libras. Em primeira instancia o que chama a atenção é a escritura de poemas utilizando a Língua Brasileira de Sinais; em segunda, o desenvolvimento de um arcabouço crítico que permite a leitura de poemas escritos em Libras. Embora a língua portuguesa acabe sendo o veículo de escolha para a produção literária dos usuários de LIBRAS, há um sistema de escrita, a VisoGrafia, desenvolvida pelo autor, que permite a escrita literária. Considerando-se que o português é na verdade uma língua segunda para os usuários de LIBRAS, esse é um passo importante na 
constituição de um corpo literário autônomo. Como teoria que informa a leitura do poema, é utilizada a numerologia pitagórica. Vale destacar a extrema originalidade do artigo.

\section{Em O SIMBÓLICO ENQUANTO PRODUTOR DE MEMÓRIA: UMA ANÁLISE DO} CONTO OS GESTOS DE OSMAN LINS, Ribanna Martins de Paula, os símbolos presentes na obra são analisados por sua capacidade de deflagrar as memorias do protagonista, a partir de um aporte teórico que contempla Jung, Frye, Eliade, Chevalier e Gheerbrant, e Bergson. André, o protagonista, está velho. Depende da esposa e das filhas e os símbolos presentes na narrativa permitem-lhe uma elaboração que a interlocução não permite pois ele não pode falar. Assim, é através dos símbolos presentes na narrativa que ocorre uma reflexão sobre a efemeridade da vida.

Carla Cristina Campos Brasil Guimarães traz à cena a peça de Ionesco através de uma de suas atualizações, aquela dirigida por Bataille, em LA CANTATRICE CHAUVE ENTRA EM CENA: UMA ANÁLISE DA MONTAGEM DE NICOLAS BATAILLE. Nessa montagem em particular, alguns dos elementos do texto teatral, como as constantes batidas do relógio e as repetições sem sentido são transpostas em uma crise de linguagem, sem dúvida uma das pedras angulares da obra de Ionesco, um dos criadores do Teatro do Absurdo. É importante destacar que a montagem em analise se repete semanalmente desde 1957, e foi assistida pela autora para a elaboração do presente artigo. Na peça, o absurdo dos diálogos se dilui para ressaltar a falta de sentido em nossas vivencias cotidianas em um mundo regido pelo acaso.

Lucas da Silva Lopes e Fabio Akcelrud Durão assinam INCONSISTÊNCIAS PRODUTIVAS: A ABORDAGEM DE SENHORA POR ROBERTO SCHWARZ. O artigo apresenta uma resenha do ensino de Robberto Schwarz que elaborou uma crítica imanente de Senhora considerando as inconsistências narrativas como produtoras de sentido. Nessa leitura a obra é considerada decodificadora de seu meio de produção e circulação não apenas pelo que a compõe formalmente, mas também pelas fissuras que ela traz. O romance como gênero é o porta voz da classe burguesa e necessariamente encontraria percalços em uma sociedade periférica e escravocrata. É essa disjunção, e o que ela ilumina da sociedade brasileira oitocentista, que centra a análise de Schwarz.

Por sua vez, Fatima Rejane de Meneses, em A PARTICULARIDADE COMO CATEGORIA ESTÉTICA E AS FRONTEIRAS ENTRE HISTÓRIA E FICÇÃO, discute a teoria elaborada por Lukács tendo como fio condutor o conceito de particularidade. Ponto de 
ligação entre o singular e o universal, é o particular que nos permite estabelecer contato com o texto literário, o que resulta na humanização efetuada pela literatura.

Em A FICÇÃO E A CONSTRUÇÃO NARRATIVA EM AUTRAN DOURADO: ALGUMAS CONSIDERAÇÕES, Nathaly de Oliveira Rufino e Rodrigo de Albuquerque Marques ensejam iluminar os vínculos entre o meio social em que se desenrolam as tramas das obras de Dourado e a linguagem utilizada pelo autor. O discurso indireto livre, frequente nelas, é uma maneira de expor a intimidade dos personagens, assim como o fluxo de consciência. A simbologia utilizada por ele também opera no mesmo nível, e isso se evidencia nos textos de crítica de Dourado, nos quais ele empreende uma análise do texto literário e de sua escritura. Para demonstrar seus pressupostos, os autores empreendem uma leitura de Lucas Procópio, bem como recorrem ao Breve manual de estilo e romance e Uma poética de romance: matéria de carpintaria.

Também trabalhando com simbologia, Silvia Gomes Bento de Mello, em SIMBOLISMOS E DESENCANTOS: ROCHA POMBO E A ESCRITA DE NO HOSPÍCIO, se debruça sobre esse romance frequentemente citado como nosso único romance simbolista. Desencantado com o projeto da modernidade, Rocha Pombo parte de suas próprias experiências, elas mesmas intrinsecamente ligadas aos fatos históricos que vivenciou - entre eles testemunhar os horrores da Revolução Federalista - para criar o protagonista, internado pelo pai por ser introspectivo e pouco atento aos ritos sociais - dificilmente um motivo de internamento, mas, como a autora aponta, a loucura, segundo Foucault, é menos um fato médico do que um fato de civilização. A filiação ao Simbolismo carrega em si uma crítica à sociedade da época e a explicita na crítica a uma racionalização que se encarrega de silenciar o dissonante, seja ele o louco ou o excluído.

Yuri Moura Moysés, em MÍDIA, MODA, MEDIANA OU MUDANÇA? Discute o impacto dos diferentes produtos de mídia de massa na formação da visão de mundo dos jovens, uma vez que eles deslocam a literatura do seu lugar formativo. Declarada objeto inessencial, a literatura perde relevância diante do império da informação - que, no entanto, falha em dar a conhecer o mundo a seus consumidores. $\mathrm{O}$ acesso à tecnologia acontece de modo precário, não lastreado por uma educação que permita articular os diferentes dados apresentados, esvaziandoos assim de sentido. Entro desse cenário, a leitura do texto literário pode suscitar reflexões e debates que de fato concorrem para a elaboração de uma visão de mundo. 
Francisco Vieira da Silva, Larissa Cristina Viana Lopes e Luan Alves Monteiro Carlos, discutem, em UM RETRATO EM PRETO E BRANCO DO SERTANEJO EM O QUINZE, DE RACHEL DE QUEIROZ, a representação do sertão, que acaba por se constituir em um personagem, ao invés de mero espaço narrativo, na medida em que a seca impacta a vida das personagens e as obriga a tomarem diferentes atitudes diante dela. Situado no Romance de 30, O quinze expõe a reação de personagens ricos e pobres à provação imposta pela seca.

Abrindo o dossiê que consta dessa edição da Agua Viva, temos Beatriz Schmidt Campos, em A INTERPRETAÇÃO NOS ESTUDOS DA CANÇÃO BRASILEIRA, nos traz uma leitura de Flores horizontais, de Oswald de Andrade e Zé Miguel Wisnik. A autora destaca o uso, contemporaneamente, das letras de música como parte integrante do estudo de língua portuguesa no ensino médio e superior, e expõe os referenciais teóricos utilizados em sua leitura: Antonio Candido, Umberto Eco e Paul Zumthor.

Em CAMINHOS DO TRÁGICO NA PEÇA VAQUEIROS, DE OSWALD BARROSO, André Luís Gomes e Fabíula Martins Ramalho utilizam um aporte teórico fundamentado em Raymond Williams, Peter Szondi e Terry Eagleton para analisar a peça Vaqueiros, do cearense Oswaldo Barroso, levada ao palco em 2002 pela Companhia Boca Rica de Teatro. A tragédia, na modernidade, pode envolver pessoas comuns, e é isso que acontece na peça. Seus protagonistas, ambos, morrem - Mira por incorporar o marido morto ao adotar a profissão dele, rompendo padrões de gênero muito estabelecidos; seu marido, por outro lado, se ressente duplamente da atitude dela: por preconceito e por ciúmes. Ele a mata; o pai dela, embora concordasse com o genro, é compelido a vingar a filha. A essa, como a chama Williams, “desordem trágica”, segue-se a morte como único desenlace possível.

Sara Lelis de Oliveira, em A IXTLAMACHILIZTLI EM MALINCHE: A TRANSMISSÃO DA SABEDORIA MEXICA, analisa o romance de Laura Esquivel, Malinche. Passada entre os anos de 1519 e 1521, durante a conquista do México pelos espanhóis, a narrativa se centra na personagem Malinalli, que passou para a história como Malinche, a intérprete de Cortez, uma das 19 escravas que ele ganhou em consequência de uma vitória. Os dados históricos disponíveis sobre ela são desencontrados e há uma tendência a considera-la uma traidora de seu povo por sua função junto a Cortez. Na obra literária ela é recriada como membro da aristocracia indígena, o que explica seu conhecimento de línguas, além de todo o aprendizado que recebeu de sua avó paterna, fora da epistemologia europeia; dessa forma, é posta em pauta uma outra forma de produção e circulação de conhecimento, 
dentro de um contexto de estudos decoloniais. No entanto, quão acuradas poderão ser as aproximações com os conceitos norteadores da cultura da América pré-hispânica, levando-se em conta que todo o conhecimento que temos sobre sua cultura veio filtrado pelos próprios invasores? Essa é a questão levantada pelo artigo.

A literatura infantil brasileira é objeto de investigação enquanto sistema, segundo Candido e a Teoria dos Polissistemas de Itamar Even-Zohar em A TRADUÇÃO NA FORMAÇÃO DO SISTEMA LITERÁRIO INFANTIL BRASILEIRO, de Lia A. Miranda de Lima. As obras traduzidas, dentro de uma literatura nacional dada, constituem um sistema que dialoga com os outros sistemas, compondo assim seu repertório. O artigo apresenta um apanhado das obras infantis em circulação no Brasil desde o segundo século IX, destacando o papel das traduções, desde aquelas vindas de Portugal até as traduções feitas no Brasil como reação à inadequação das anteriores; delas surgirá uma literatura infantil nacional cujo nome de maior relevo é Monteiro Lobato. Assim, o sistema das obras traduzidas teve importância fundamental para o desenvolvimento de uma literatura infantil brasileira.

Ana Clara Vieira da Fonseca apresenta uma revisão da obra crítica de Antonio Candido em LITERATURA E MILITÂNCIA: A SOCIEDADE NA CRÍTICA DE ANTONIO CANDIDO. Partindo de Textos de intervenção, que consta de textos publicados por Candido em jornais e outros meios de grande circulação, Vinícius Dantas organizou essa obra, que permite retraçar os percursos críticos, bem como teóricos, percorridos por Candido, o artigo presta uma homenagem não apenas a sua produção acadêmica e intelectual, mas também a sua participação na vida intelectual e política do país.

\section{Em PARA ALÉM DOS CICLOS DE SANGUE: TRANSGRESSÃO E} TRAGICIDADE EM ANTÍGONA, DE SÓFOCLES, Bárbara Cristina dos Santos Figueira utiliza como aporte teórico Bertold Brecht, György Lukács e Raymond Williams, para analisar a peça Antígona, parte da Trilogia Tebana. A autora afirma ser essa peça um libelo pela liberdade, na qual a forma da tragédia funciona como um amplificador da defesa dos atos de consciência, mesmo, ou principalmente, quando se opõe à autoridade constituída.

Cacilda Bonfim, em OSMAN LINS: LITERATURA E POLÍTICA, utiliza Barthes e Bobbio como aporte teórico para analisar A rainha dos cárceres da Grécia, destacando as implicações políticas que o romance traz não apenas através, mas também por sua própria linguagem. Assim, tanto forma como conteúdo nesse romance que, como as outras obras de 
Osman Lins, se singulariza por sua forma literária sofisticada, concorrem para discutir os eventos da história do Brasil contemporânea a sua publicação, bem como propõe questões mais atemporais.

\section{MARGINALIA E HIPERTEXTO: O PERSONAGEM COMO CRÍTICO EM S. OU O} NAVIO DE TESEU, de Vítor Castelões Gama, analisa o romance da autoria do cineasta J. J. Abrams e do escritor Doug Dorst como uma volta à materialidade do livro ao mesmo tempo que incorpora, na sua linguagem, características de uma poética digital. No caso, trata-se de inserções feitas por leitores de uma obra fictícia, trazendo diferentes linguagens - segundo Katherine Hayles, utilizada como aporte teórico, uma das características do livro digital. A intenção confessa dos autores era a de criar um livro imersivo, que conferisse agencia a seus leitores.

Rafael Gazzola de Lima, em UMA SÓ PRECE? A CANÇÃO COMO GESTO SOCIAL EM PONTO DE PARTIDA, analisa a canção Prece, de Gianfrancesco Guarnieri, parte da peça de sua autoria, e de Sérgio Ricardo, Ponto de Partida, que se refere ao assassinato de Vlado Herzog, sob tortura, durante a ditadura militar. Como referencial teórico, Lima utiliza o conceito de gesto social, de Bertold Brecht, bem como o de performance, segundo Paul Zumthor, para a especificidade da análise de uma canção. Lima também estabelece um paralelo à época de escritura e representação da peça, 1976, e os tempos que correm; sua hipótese de leitura é de que Ponto de partido põe em questão as relações entre a endêmica violência da sociedade brasileira e os mecanismos de manutenção dos privilégios de classe.

GOSTAR DE POESIA: PROJETO EDUCACIONAL CORA CORALINA, de Nadine Alves Ferreira, traz o relato de ume experiência no trato da literatura em uma escola particular em Formosa-GO. Enquanto o hábito da leitura é menos disseminado do que o desejável, parte das atribuições da escola, e do professor de literatura, é evidenciar que o texto literário extrapola a memorização para a avaliação e se estende para a própria elaboração de uma visão de mundo pelo leitor. Utilizando a teorização elaborada por Regina Zilberman sobre o ensino de literatura e de Todorov sobre a leitura, a autora reflete sobre a experiência de uma roda de leitura que utilizou poemas de Cora Coralina como corpus, e da qual participaram docentes de outras áreas, em um viés multidisciplinar. 
Por fim, gostaria de destacar que, seja por seu corpus, seja pelo aporte teórico utilizado, todos os artigos da presente edição da Revista Água Viva deixam transparecer seu compromisso com a democracia.

Profa. Dra. Cintia Carla Moreira Schwantes Editora-Chefe da Revista Água Viva 